\title{
SAR observing large-scale nonlinear internal waves in the White Sea
}

\author{
Igor Kozlov ${ }^{\mathrm{a}, \mathrm{b}, *}$, Dmitry Romanenkov ${ }^{\mathrm{c}}$, Alexei Zimin ${ }^{\mathrm{a}, \mathrm{c}}$, Bertrand Chapron ${ }^{\mathrm{a}, \mathrm{d}}$ \\ a Satellite Oceanography Laboratory (SOLab), Russian State Hydrometeorological University, Malookhtinsky \\ Prospect 98, St. Petersburg 195196, Russian Federation \\ ${ }^{\mathrm{b}}$ Klaipèda University, H. Manto g. 84, LT-92291 Klaipedda, Lithuania \\ ${ }^{c}$ St. Petersburg Branch of P. P. Shirshov Institute of Oceanology RAS, St. Petersburg, Russian Federation \\ d Institute Francais de Recherche pour l'Exploitation de la Mer, BP 70, 29280 Plouzane, France \\ *: Corresponding author : Igor Kozlov, tel.: + 78123725085 ; email address : igor.eko@gmail.com \\ dmromanenkov@yandex.ru ; bertrand.chapron@ifremer.fr
}

\begin{abstract}
:
The compiled archive of synthetic aperture radar (SAR) images acquired by the Advanced SAR (ASAR) onboard the Envisat satellite over the White Sea during the extended summer periods (MaySeptember) between 2007 and 2011, provides the first detailed analysis of 2-D patterns of internal waves (IWs) in the White Sea. Unambiguously, the primary region of IW activity is the southwestern (SW) Gorlo Strait (GS). IW packets emerging from this area are regularly observed to reach crest lengths up to $200 \mathrm{~km}$, and also to propagate a few hundred kilometers from their origin. Model results confirm that large-scale IWs can be generated every tidal cycle and are able to cross the entire sea. As suggested, the source of these packets is governed by the intense dynamics of the frontal zone in the tidal cycle over local complex bottom. As further revealed, these large-scale IWs cascade into intense large-amplitude short IW packets on the shoaling White Sea shelf, significantly impacting vertical turbulent exchange and the overall hydrology.
\end{abstract}

\section{Highlights}

The SW Gorlo Strait is a major hotpoint for generation of nonlinear internal waves. Short internal waves evolve into large-scale packets crossing the sea. Internal waves strongly impact the vertical mixing and hydrology of shelf areas.

Keywords: SAR imaging ; Nonlinear internal waves ; The White Sea ; Vertical mixing 
The White Sea is the smallest sea of the Arctic Ocean with a complex configuration of bottom topography and coasts. Tidal dynamics is the most important factor affecting its hydrology. Tidal flow velocities reach $180 \mathrm{~cm} / \mathrm{s}$ in strait regions and in some shallow zones (Glukhovsky, 1991). These two main factors, complex bottom and strong tidal currents, provide suitable conditions for generation of nonlinear internal waves, significantly impacting the hydrology of the upper ocean through the transferring energy from tides to turbulent mixing. In the White Sea they are particularly important for sub-marine navigation and construction, formation of the water structure and the maintenance of the life activity in marine ecosystems (Zimin, 2012). However, internal waves in general, and short nonlinear IWs (NIWs) particularly, are still poorly investigated (Kagan and Timofeev, 2005; Serebryany et al., 2009; Zimin, 2012).

Numerical studies (Semenov and Luneva, 1999; Kagan and Timofeev, 2005) address surface and internal tides in the White Sea, and two generation areas of internal tidal waves (ITWs) have been identified - north of the inlet to the Onega Bay where the bottom slopes are critical or supercritical, and the outlet from the Gorlo Strait (GS) where the bottom slopes are subcritical, with strong tidal barotropic velocities. Yet, for both areas, ITWs shall dissipate locally due to proximity to the critical latitude (Kagan and Timofeev, 2005).

Recent in situ experiments have been conducted to study the characteristics of short-period IWs in the White Sea. Serebryany et al. (2009) reported a train of short-period IWs in the Dvina Bay with maximum amplitude of about $3 \mathrm{~m}$, and Zimin $(2012,2013)$ detected internal bore and intense short-period IWs in the relatively shallow Zapadnaya Solovetskaya Salma (ZSS) Strait (see Fig.1).

From the remote sensing perspective, space-borne Synthetic Aperture Radars (SAR) are known to be suited for the IW detection and analysis (e.g., Apel et al., 1983; Fu and Holt, 1984; da Silva et al., 2007; Klemas, 2012). From this point, the White Sea has still remained totally unexplored and currently is not presented in the regionally-detailed atlas of the oceanic internal waves (Jackson, 2004). Our study, therefore, extends the global observations of short-period IW fields to the high northern latitudes in the Arctic Ocean.

Building on a recently compiled archive of Envisat Advanced SAR (ASAR) images acquired during the warm season over the White Sea between 2007 and 2011, about two hundred of SAR images have been processed to provide the first detailed analysis of 2-D patterns of IWs in the White Sea. As found, packets of short-period IWs are widely geographically distributed, and the southwestern (SW) part of the Gorlo Strait is clearly a hotspot for their generation. Also revealed, and supported by model calculations, nonlinear IW packets generated in the SW Gorlo Strait presumably with $\mathrm{M}_{2}$ tidal frequency can evolve into large-scale IW trains crossing the entire sea. Possibly related to intense nonlinear IWs registered in situ on the western White Sea shelf, these events can provide a significant enhancement of shelf water mixing and a key role in biological primary production.

\section{Climatology}

Between 2007 and 2011, 225 distinct short-period IW packets are detected within 220 Envisat ASAR images taken over the region. Most IW packets were observed between July $15^{\text {th }}$ and August $15^{\text {th }}$, i.e. under favorable stratification and wind conditions for their both generation and detection in the SAR images. The earliest (latest) IW detection occured on May $7^{\text {th }}$ (September $8^{\text {th }}$ ), 2010. A climatology distribution of leading waves of all detected IW packets is shown in Fig. 1. Two groups are distinguished according to the wavelength of the leading wave (denoted as $\lambda_{1}$ on Fig. 1), with black curves corresponding to wavelengths up to $1 \mathrm{~km}$, and red curves for those exceeding $1 \mathrm{~km}$. The latter wave packets are typically larger in all spatial domains - higher crest lengths up to $200 \mathrm{~km}$, packet lengths and interpacket separations.

Short IWs are mostly found over the shelf areas with abrupt depth changes from 50 to 100 meters. Most IWs were observed in the form of internal solitary waves (ISWs) with rank-ordered wavelengths in the packet, typical in the coastal ocean (Jackson, 2004). Individual packets typically contained 3-5 (max. 20) 
waves with intersoliton separations of 0.2 to $2.5 \mathrm{~km}$. Successive packet separations are between $5-20 \mathrm{~km}$, reaching $30-40 \mathrm{~km}$ for the individual cases. The crest lengths range between $5-80 \mathrm{~km}$, the longest wavefronts being about $200 \mathrm{~km}$ long, very large for the small White Sea, but comparable in size with the large nonlinear ISWs found worldwide (Jackson, 2004). SAR images could contain several (up to six) identical consequent IW packets, likely originating from the same generation point. These quasi-periodic patterns suggest a tidal origin, are found over the whole basin, except the shallow Onega Bay.

The southwestern part of the Gorlo Strait corresponds to the highest IW activity. Fig. 2 presents an example of ASAR image (HH-polarization) taken in Wide Swath Mode (WSM) on August 13, 2010 showing clear surface manifestations of several internal wave packets in this part of the sea. While the SAR image reveals many small-to-large scale IW packets propagating to different directions, major IW trains travel southwest from the Gorlo Strait towards the Basin, with crest lengths exceeding $100 \mathrm{~km}$ and inter-packet distances between 10-30 km. At the Gorlo Strait, water masses exchange between the Barents Sea and the White Sea (e.g., Shapiro et al., 2003), and hence a complex frontal zone is located in its southwestern part, where the relatively cold (and more saline) mixed strait waters from the northeast adjoin the warmer (and less saline) stratified Basin waters located to the southwest from the frontal boundary. A sharp density front is also formed along the Winter Coast (denoted on Fig. 1) by the Northern Dvina river outflow, bringing fresh and warm waters to the Dvina Bay and farther to the SW Gorlo Strait. Both frontal features are well visualized with the Terra MODIS sea surface temperature (SST) map acquired on August 4, 2010 (Fig. 3). Interesting to note, that no IW packets (except for a single occurrence) were found within the Strait (apart its SW part), as the sea waters there are usually rather well mixed (Shapiro et al., 2003).

In the Basin area, strongly stratified in summer time (Semenov and Luneva, 1999; Pantiulin, 2012), IWs likely occur in the shallower eastern part of the Basin, over depths up to 100 meters. Some IW activity occurs in the vicinity of the Solovetsky Archipelago including two pronounced tidal mixing areas in the Vostochnaya and Zapadnaya Solovetskaya Salma straits (denoted on Fig. 1). More surprisingly, a dozen of short nonlinear IW packets have been detected in the shallow, and assumed well-mixed, Onega Bay. Here, IW locations coincide with the fresh Onega river front. Finally, no IW occurrences were found in the deep and strongly stratified Kandalaksha Bay. As analyzed, west-southwest IW propagation is statistically dominant over the entire sea. Less frequently, IWs travel in the opposite eastward-southeastward direction in the eastern Basin part and along the Tersky Coast. The clear increase of the wavelength and the crest length is evident for the leading waves when packets progress seawards. Over the shallow shelf, $20-80 \mathrm{~m}$ depth, the wavelength (crest length) is between $300-800 \mathrm{~m}(10-50 \mathrm{~km})$, whereas IW packets with intersoliton wavelength of $1-2.5 \mathrm{~km}$ (red curves on Fig.1) and crest length of $80-200 \mathrm{~km}$ are found over the deeper eastern and central Basin parts with 80-200 m depths.

Overall, observed radial spreading and evolution of ISW packets is a typical feature of tidally generated internal waves while they propagate (e.g., da Silva et al., 2011). However, IW packets from certain directions were observed to travel farther offshore and evolve into large-scale packets denoted by red curves in Fig. 1. Most of such large-scale packets originate from the SW Gorlo Strait, travel to the Basin and, in specific cases, are able to reach the western sea shelf.

\section{Large-scale internal waves}

An example of NIWs packets crossing the entire sea is illustrated with the Envisat ASAR WSM image (HHpolarization) acquired on July 21, 2010 (Fig. 4). The coverage area of the cropped ASAR image (Fig. 4, a) is $210 \times 85 \mathrm{~km}$. Schematic of the observed ISW packets with some supplementary information is shown in Fig. 4 (b). Despite pronounced variations of the local winds, surface manifestation of five distinct consecutive IW packets (named $\boldsymbol{A}, \boldsymbol{B}, \boldsymbol{C}, \boldsymbol{D}, \boldsymbol{E}$ ) with rank-ordered solitary waves is clearly distinguished. Several, but less evident, ISW packets are observed on the western shelf in the Zapadnaya Solovetskaya Salma Strait. These ISW packets merge onto one larger ISW packet, denoted with $\boldsymbol{F}$ on Fig. 4 (b). Depending on local wind conditions, the SAR manifestations of internal waves range from double sign (packets $\boldsymbol{A}, \boldsymbol{B}, \boldsymbol{C}$ ) to single negative (packets $\boldsymbol{D}, \boldsymbol{E}, \boldsymbol{F}$ ) signature modes (for details see e.g. da Silva et al., 1998). One may also note other wave-like patterns in the upper part of this SAR image, which appear to be the surface manifestations of atmospheric gravity waves as they have rather broad dark bands of decreased backscatter (Alpers and Huang, 2011). 
An overall propagation trajectory follows from the SW Gorlo Strait where the packet $\boldsymbol{A}$ is located, to the Basin (packets $\boldsymbol{B}, \boldsymbol{C}, \boldsymbol{D}$ ) towards the eastern shelf (packets $\boldsymbol{E}, \boldsymbol{F}$ ). Moving seawards, from $\boldsymbol{A}$ to $\boldsymbol{D}$, the number of solitons increases (2-20), as well as the wavelength of the leading wave $(0.2-2.5 \mathrm{~km})$ and crest length $(5-200 \mathrm{~km})$. The inter-packet distances (and phase speeds of IW packets, assuming semi-diurnal generation frequency) between $\boldsymbol{A}$ and $\boldsymbol{D}$ have an increasing trend, however, they change a little randomly (note a reduction of phase speed between the wave packets $\boldsymbol{B}$ and $\boldsymbol{C}$, followed by an increase in wave speed between $\boldsymbol{C}$ and $\boldsymbol{D}$ ) which may be caused by small changes in ambient environmental conditions at the generation site resulting in different amplitudes of the waves and, hence, their propagation speeds. The total travel distance is nearly $200 \mathrm{~km}$ which is about the sea width at $65.5^{\circ} \mathrm{N}$.

As mentioned above, a sharp density front is located at the southern outlet of the Gorlo Strait (see MODIS SST map on Fig. 3). The location of the front boundary is also quite well detectable from the same ASAR roughness image as narrow dark bands, presumably associated with dampening of short wind waves by surfactants accumulated in the surface current convergence zone at the frontal boundary (see e.g. Johannessen et al., 2005; Kozlov et al., 2012), and is marked on Fig. 4 (b) with red line.

Packet $\boldsymbol{A}$ is about $25 \mathrm{~km}$ from the front. The front structure and its tidal dynamics have been detailed by ship-borne CTD measurements (Fig. 5) along the transect I-II shown as blue line with crosses on Fig. 4 (b). Weakly stratified Gorlo Strait water with salinity $27.6-28 \mathrm{psu}$ and temperature $3.5^{\circ} \mathrm{C}$ and well-stratified Basin water with vertical salinity (temperature) change from 18.3 to 28.2 psu $\left(-0.5\right.$ to $1{ }^{\circ} \mathrm{C}$ ) have been identified. Position and properties of the front are also influenced by the low salinity and warm Dvina Bay waters. Main water masses are associated with two major currents - the outgoing fresh current along the Winter Coast and the incoming current along the Tersky Coast (see Fig. 3), maintaining the salinity balance (Shapiro et al., 2003). The flow character and mixing processes here are significantly affected by strong tides and ragged bottom topography.

During the ebb tidal current (Fig. 5, a), stratified waters flow out the Basin forming vertical temperature gradient up to $0.5^{\circ} \mathrm{C} / \mathrm{m}$ with a thermocline located at $10-12 \mathrm{~m}$ depth. Warm and fresh waters of the Dvina Bay are located in the surface 7-10 m layer, approximately in the middle of the strait. The usual location of these fresh waters is along the Winter Coast (as seen on Fig. 3) which is disturbed at the time of observations by strong northwesterly winds. During the flood current (Fig. 5, b), stratified waters modified by the interaction with the mixed strait waters, are flowing back and cover the whole strait width, leading to considerable horizontal shift of the front location. As a result, the temperature of the upper layer is about 6$7{ }^{\circ} \mathrm{C}$, vertical temperature gradient becomes weaker and a less pronounced thermocline is now at the depths between 3 and $8 \mathrm{~m}$. Finally, an underwater bank elongated along the main strait axis is located approximately at $40 \mathrm{~m}$ depth. Altogether, interactions between the barotropic tidal flow with this thermohaline front lead to pronounced horizontal and vertical variations of isopycnal surfaces during the tidal cycle. In combination with topographic effects, generation of the large nonlinear IW packets may thus be expected.

As detected, the distance between packets $\boldsymbol{A}-\boldsymbol{B}$ is about $30 \mathrm{~km}$ and can correspond to the $\mathrm{M}_{2}$ wavelength value, between 15-30 km, estimated using the vertical density profiles (Fig. 5, c) in the ebb (black solid line) and flood (black dashed line) phases of semi-diurnal tide, and from climatology data (grey solid line for July, and grey dashed line for August).

To assess whether environmental parameters and bottom topography would enable the propagation of IW packets over large distances, the generalized Korteweg-deVries (KdV) equation can be used (e.g. Grimshaw et al., 2007):

$$
A_{t}+C_{0}(x) A_{x}+\alpha(x) A A_{x}+\alpha_{1}(x) A^{2} A_{x}+\beta(x) A_{x x x}+\left[C_{0} / 2 \gamma(x)\right] \gamma_{x} A-\varepsilon A_{x x}=0
$$


where $A(x, t)$ is a wave amplitude, $C_{0}(x)$ - a linear wave speed, and parameters $\alpha(x), \alpha_{1}(x), \beta(x), \gamma(x)$ and $\varepsilon$ are the coefficients for the nonlinear, higher order nonlinear (cubic), dispersion, transformation, and dissipation effects.

Observations from space and field experiments have demonstrated the influence of topography and horizontally variable stratification on the evolution of ISWs (Liu et al., 1998; Zheng et al. 2001; Zhao et al., 2003). For shallow water approximation $h / l \ll 1$, the KdV equation and its generalizations are widely used and shown to be effective for investigation of propagation and transformation of internal waves in the shelf and coastal ocean (e.g., Osborne and Burch, 1980; Liu et al., 1998; Small et al., 1999; Grimshaw et al., 2004; Holloway et al., 1997). Moreover, the KdV equation can be easily generalized for horizontally inhomogeneous fluid and irregular bathymetry leading to an equation of the same form, but with the coefficients varying in the horizontal space (Holloway et al., 1997; Grimshaw et al., 2007; Liu et al., 1998; Small, 2001).

In our case, we use a numerical model based on the generalized KdV equation in a two-layer approach. This choice overcomes the lack of direct observations of continuous stratification in the deep basin of the WS, and is sufficient to study the effects of propagation and transformation of the nonlinear IWs under the influence of variable bottom and pycnocline depth after their generation in the SW Gorlo Strait.

Along the IW propagation trajectory, the one-degree resolution ESIMO climatological database (http://data.oceaninfo.info/atlas/Beloe/1 1.html) indicates a steady summer pycnocline at depths 17-25 m between the surface and intermediate water masses. Also bottom water mass with a density close to intermediate water density is found below $120 \mathrm{~m}$. A two-layer system of upper quasi-homogeneous and lower layers with thicknesses $h_{1}$ and $h_{2}$, respectively, can thus be used (Liu et al., 1998; Small, 2001):

$$
\begin{gathered}
C_{0}=\sqrt{\Delta \rho g h_{1} h_{2} / \rho\left(h_{1}+h_{2}\right)}, \\
\alpha=\left[3\left(h_{1}-h_{2}\right) / 2\left(h_{1} h_{2}\right)\right] C_{0},(3) \\
\alpha_{1}=\left[-3\left(h_{1}^{2}+h_{2}^{2}+6 h_{1} h_{2}\right) / 8\left(h_{1} h_{2}\right)^{2}\right] C_{0}, \\
\beta=\left(h_{1} h_{2} / 6\right) C_{0}, \\
\gamma=\left\{C_{0}(0) C_{0}^{-1}\left[h_{1}^{-1}(0)+h_{2}^{-1}(0)\right] /\left[h_{1}^{-1}+h_{2}^{-1}\right]\right\}^{3},
\end{gathered}
$$

where $g$ is the gravitational constant, $\rho$ is water density, and $\Delta \rho=\rho_{2}-\rho_{1}\left(\rho_{2}>\rho_{1}\right)$ is density difference between two layers.

With constant coefficients $\alpha, \beta, \gamma$ and with $\alpha_{1}=\varepsilon=0$, the solution of Eq. (1) simplifies to:

$$
A(x, t)=A_{0} \sec h^{2}\left[\left(x-c_{1} t\right) / \lambda_{s}\right]
$$

where $A_{0}$ is the maximum amplitude, $\lambda_{s}=\sqrt{12 \beta / A_{0} \alpha}$ is a soliton half-width, and $c_{1}=c_{0}+A_{0} \alpha / 3$ is a phase speed.

Our model neglects the effect of Coriolis force, as commonly accepted if the characteristic scale of internal waves $l \ll L_{R}$, where $L_{R}=C_{0} / f$ is the internal Rossby radius, and $f$ is the Coriolis parameter. For the soliton in waveform (7), the characteristic scale $l$ is the soliton half-width $\lambda_{s}$ to be directly evaluated from the SAR image (see e.g. Small et al., 1999; Zheng et al., 2001). For the waves observed in the White Sea 
Basin (e.g. IW packet $\boldsymbol{C}$ on Fig. 4), I can be estimated from the SAR image (see Fig. 6 , a) as $l=D / 1.32 \approx$ $300 \mathrm{~m}$ (Small et al., 1999), where $D \approx 400 \mathrm{~m}$ is the distance from peak to trough backscatter of the leading wave of packet $\boldsymbol{C}$ on Fig. 6 (b).

Our study region is situated in the high northern latitudes, mean latitude $\bar{\theta}=65.5^{\circ} \mathrm{N}$, and, accordingly, $L_{R} \approx$ $6 \mathrm{~km}$, therefore, some comments on the influence of the Earth's rotation on IW propagation should be made. Two cases to account for the Coriolis effect are usually distinguished, namely "strong rotation" when $l>L_{R}$, and "weak rotation" when $l \leq L_{R}$ (e.g., Ostrovsky, 1978; Helfrich, 2007; Grimshaw and Helfrich, 2008; Farmer et al., 2009; Grimshaw et al., 2013). In the case of "weak rotation" applicable to our observations (as $l \ll L_{R}$ ), the theory can be modified for short-scale waves (relative to the Rossby radius) so that the effects of rotation balance with weakly nonlinear and dispersive effects.

According to Helfrich (2007) the effect of the "weak rotation" for short waves must not be ignored if $\left(l / L_{R}\right)^{2}=O\left(|A| / h_{S}\right)$, where $A$ is the amplitude of internal waves, $h_{s}$ is the characteristic depth. Taking $L_{R}=$ $6 \mathrm{~km}, l=300 \mathrm{~m}, h_{s}=100 \mathrm{~m}$, and $|A|=5 \mathrm{~m}$, we obtain $\left(|A| / h_{s}\right)=0.05$ and $\left(l / L_{R}\right)^{2}=0.0025$, meaning that $\left(l / L_{R}\right)^{2} \ll O\left(|A| / h_{s}\right)$, and the rotation is not important.

In addition, the relative importance of the rotation term as compared to the nonlinear term may also be measured using Ostrovsky number $O_{s}$, which is calculated as (Farmer et al., 2009):

$$
O_{s}=-24 \pi^{2} C_{0} \alpha|A| / f^{2} l^{2},
$$

where $\alpha$ is the nonlinearity coefficient in Eq. (1). For the mean values of parameters along the path of IW packets $A-E$, taking $\alpha \approx-0.04 \mathrm{~m}^{-1} \mathrm{~s}^{-1}, C_{0} \approx 0.7 \mathrm{~ms}^{-1}, l \approx 300 \mathrm{~m}$, and $|A| \approx 4 \mathrm{~m}$, we obtain $O_{s} \approx 1 \times 10^{3}$, i.e. nonlinear effects will dominate the rotation. In our calculations the ratio of the nonlinear term to the nonhydrostatic dispersion term does not exceed 10 , and the rotational effects are locally small in comparison with the nonlinear and nonhydrostatic effects.

Using Eq. (1), we can focus on the effects of the variable hydrology and depth as well as dissipation to determine the "lifetime" of short-period internal waves propagating after their generation. Along the presumed trajectory, climatic density of the upper and lower layers are $\overline{\rho_{1}} \approx 1018.2 \mathrm{kgm}^{-3}$ and $\overline{\rho_{2}} \approx 1020.3$ $\mathrm{kgm}^{-3}$ accordingly, with $\Delta \rho \approx 2 \mathrm{kgm}^{-3}$, except for the shallow shelf to the west of packet $\boldsymbol{F}$ where $\overline{\rho_{2}} \approx$ $1019.9 \mathrm{kgm}^{-3}$ and $\Delta \rho \approx 1.3 \mathrm{kgm}^{-3}$ correspondingly.

However, the summer 2010 was anomalously warm over the NW Russia, and Zimin (2012) reported $\Delta \rho$ being 1.5 larger the mean climatic value for the beginning of August in the area close to packet $\boldsymbol{F}$ location. Such proportionality for the density contrast along the propagation from $\boldsymbol{A}$ to $\boldsymbol{F}$ is further used in the model calculations. For packets $\boldsymbol{A}$ and $\boldsymbol{B}$ having $h_{1} \approx 18 \mathrm{~m}, h_{2} \approx 56 \mathrm{~m}, \Delta \rho=3 \mathrm{kgm}^{-3}$, with $\lambda_{s}=100 \mathrm{~m}$ from the SAR image and $A_{0}=-5 \mathrm{~m}$, we obtain $c_{1} \approx 0.69 \mathrm{~m} / \mathrm{s}$ and distance $L_{A B} \approx 31 \mathrm{~km}$, in good agreement with the observed value (Fig. 4).

Eq. (1) is then solved numerically on a regular grid with the resolution $\Delta x=20 \mathrm{~m}$ and $\Delta t=15 \mathrm{~s}$, the viscosity coefficient $\varepsilon=0.0025 \mathrm{~m}^{2} \mathrm{~s}^{-1}$, and the total integration time of $75 \mathrm{~h}$. A train of two consecutive waves (similarly as observed in the SAR image for the packet $\boldsymbol{A}$ ) with amplitudes $A_{0}$ of -5 and -4 meters and the distance between them $400 \mathrm{~m}$ appears at $x=0$ with tidal periodicity of $12.42 \mathrm{~h}$.

Results, Fig. 7, confirm that the incoming solitons undergo a number of changes as they propagate seaward and then shelfward. Their amplitudes strongly reduce, becoming broader and flatter, as the transformation coefficient $\gamma(x)>1$ over the most part of the trajectory. Between $\boldsymbol{A}$ and $\boldsymbol{B}$, nonlinearity prevails over dispersion and evolution of solitons is accompanied by the formation of a tail with short-scale oscillations, as further observed in the SAR image, e.g. for packet $\boldsymbol{C}$ (see Fig. 6). After propagating 160 kilometers, the situation changes: the coefficient $\gamma(x)$ sharply decreases due to the shoaling, dispersion 
coefficient $\beta(x)$ weakens, the coefficient of square nonlinearity $\alpha_{1}(x) \rightarrow 0$ (as $h_{1}=h_{2}$ at $x=X_{\text {end }}$ ), and cubic nonlinearity $\alpha_{1}(x)$ becomes significant. As a result, the amplitudes sharply increase, and the fission occurs to pitch several waves in the shallow water.

As obtained, Fig. 7 further shows explicit coincidence between model and SAR observations. These results confirm that nonlinear IWs observed in the SAR image are related with tidal dynamics at the SW Gorlo Strait front, generated once per $\mathrm{M}_{2}$ tidal cycle. Under the background conditions relevant to stratification during abnormally warm summer, IW packets can travel over a considerable distance without significant decay and destruction, and reach the western sea shelf.

\section{Implication}

The effects of these large-scale nonlinear IWs are highlighted with vertical CTD profiles sampled in the ZSS Strait, conducted on August 8-10, 2010 (see Zimin, 2012). In situ measurements registered the propagation of a packet of intense NIWs with the rank ordered amplitudes of 14-17 m (Fig. 8), about half the total depth in this area. The phase speed of this train was about $0.9-1.2 \mathrm{~m} / \mathrm{s}$ with the period of about $10-20 \mathrm{~min}$, corresponding to $\sim 0.6-1.4 \mathrm{~km}$ wavelength in agreement with the observed wavelength of solitary waves in the southern part of the packet $\boldsymbol{F}(0.8-1.5 \mathrm{~km})$. Such trains of intense IWs were registered every tidal cycle. As visually registered, IWs were further accompanied by the slick bands on the sea surface, and similarly detected in the SAR image on Fig. 4 as dark (i.e. low backscatter) elongated bands resulted from short waves dampening by surface films accumulating in the surface current convergence zones associated with IW propagation (see e.g. da Silva et al., 1998; Kudryavtsev et al., 2005). Numerical simulations show that these intense events result from the evolution of large-scale IW packet entering the shoaling shelf.

For these observations, the coefficient of vertical turbulent exchange and its variation within the tidal cycle are estimated to be $0.0011-0.0017 \mathrm{~m}^{2} / \mathrm{s}$ in the time intervals when NIWs appear, i.e. twice higher averaged values over the tidal period, both higher than the background value. Similar estimates (Zimin, 2013) confirmed the enhanced vertical turbulent exchange at different locations on the White Sea shelf including the area in the ZSS strait. At the same time, the coefficients were significantly lower when no IWs were registered. This result is a well-known effect (Moum et al., 2003), however, in our case, nonlinear IWs are non-local, crossing the whole basin, and affect the vertical mixing of the shelf waters located as far as 200 $\mathrm{km}$ away in the western White Sea.

\section{Discussion}

Our model study proves that observed large-scale IWs are initially generated in the SW GS frontal area every tidal cycle. However, the generation mechanism for these waves remains unclear. As was shown in Figs. 1-2, the area of the SW GS is ubiquitous in amount of regularly observed IW packets possessing the variety of spatial scales, travel directions and inter-packet separations $(5-30 \mathrm{~km})$ which potentially address different ISW generation mechanisms (and generation periodicity) including lee wave, transformation of baroclinic tide, resonance in the transcritical flow, or tide-front interactions (Jackson et al., 2012).

In general, some of these IW trains can be of non-tidal origin, e.g. generated due to periodic disturbances of atmospheric pressure and wind stress. However, assuming the dominant role of tide, characteristics of the observed ISW packets are still strongly related to the changes in stratification, background currents, wind conditions and 14-day spring-neap modulation of barotropic flow strength (e.g., Simpson and Hunter, 1974; Gerkema, 2002; Kurapov et al., 2010).

Also important to note, that our study region (mean latitude $\left.\bar{\theta}=65.5^{\circ}\right)$ is close to the critical latitude $\left(\theta_{c}=\right.$ $74.5^{\circ}$ ), where the internal (baroclinic) tide is suppressed by the Earth's rotation, and the energy of the barotropic tide is transferred to the short-scale waves not subjected to the rotation of the Earth (Vlasenko et al., 2003; Morozov and Paka, 2010). Typically these waves develop in the form of lee waves propagating 
from the source of generation every tidal cycle as packets of short-period IWs, provided that nonlinearity of the generated waves and tidal currents are sufficiently strong.

In our case nonlinear IWs are generated at the frontal area located over the bank. In general, their generation could be explained owing to the lee wave mechanism (Maxworthy, 1979) when the IW packets are released from the lee side of the bank once per tidal cycle (Chereskin, 1983). Available experimental data show sufficiently high Froude numbers supporting the possible role of this mechanism for some of the observed internal waves. However, the differing character of IW travel directions and inter-packet distances for another part of observations also suggests more frequent generation (than once per tidal cycle), and likely other than lee wave generation mechanism.

Generation of the long-living NIW trains as a result of an evolution (steepening) of the baroclinic tide, when both propagate together with a fixed phase relationship (Apel, 1985; da Silva et al., 2011; Jackson et al., 2012), appears not to be feasible at this latitudes and would contradict model findings (Kagan and Timofeev, 2005) suggesting that internal tides generated in the SW GS dissipate locally within 15-20 km from the generation area due to the proximity to the critical latitude.

Bearing in mind the existence of strong tidal flow, local complex bottom and frontal zone in the SW GS, it appears more reasonable to consider that some of the observed nonlinear wavetrains, including those evolving into the large-scale IWs, can be resonantly generated here in the transcritical regime (Grimshaw et al., 2007) when the Froude number $F=U / C_{0} \approx 1$ (where $U$ - flow velocity, and $C_{0}$ - the phase speed of IWs). Under this mechanism, several IW packets can be generated as tidal flow passes through the transcritical regime $(0.9<F<1.1)$ during the acceleration and deceleration phases of the ebb tidal current (da Silva and Helfrich, 2008). In SAR images it was manifested in the form of IW packets with slightly different propagation directions and distances smaller than predicted under a semi-diurnal generation periodicity. In such a case, short IW packets can be generated several times during the tidal period, just once or never, depending on the conditions for the resonant generation. In the SW GS tidal current velocities can be as high as $0.5-1 \mathrm{~m} / \mathrm{s}$ in the area of the frontal zone, which points to the possibility of the resonant generation of multiple-wave IW packets including those evolving into the large-scale IW trains observed in the SAR images on Fig. 2 and Fig. 4.

Finally, nonlinear internal waves can also be intensively generated in the frontal zones due to the tide-front interaction (Nash and Moum, 2005; Groeskamp et al., 2011). Nash and Moum (2005) relate the generation of IWs (propagating downstream) with frontal instability caused by tidal modulation of speed and direction of the river plume, whereas Groeskamp et al. (2011) acknowledge the occurrence of internal waves in the highly dynamic estuary owing to the both resonant generation and lee wave mechanisms. The latter suggests that for the same frontal area different generation mechanism can be responsible for the generation of nonlinear internal waves.

The presence of a strong density front over the bank in the SW GS together with the availability of strong tidal currents indeed challenges the identification of IW generation mechanism, however, we suggest that the resonant generation and frontal mechanisms are the two best candidates to explain the generation of nonlinear IWs in the SW Gorlo Strait. Yet, lack of detailed in situ measurements precludes inferring the exact mechanism, and further investigations are certainly needed.

\section{Conclusions}

The compiled archive of satellite Envisat ASAR images, acquired over the White Sea during periods when the water column was thermally stratified in 2007-2011, provides the first detailed analysis of 2-D patterns of IWs in the White Sea. The highest IW activity is observed in the southwestern part of the Gorlo Strait the main hotspot for the generation of nonlinear internal waves in the White Sea, where IWs have a variety of spatial scales, propagation directions and inter-packet distances. 
Throughout the SAR survey, we systematically observe IW packets, first detected on the shallow shelf, and further evolving into the large-scale packets while they travel seawards. Notably, a single SAR image is capable to capture up to six IW trains presumably generated at the consequent tidal cycles which was rarely reported elsewhere in the literature. These IWs are characterized by the crest lengths as long as 200 $\mathrm{km}$, the wavelength of the leading waves up to $2.5 \mathrm{~km}$ and the inter-packet separations of $30-40 \mathrm{~km}$. Most of such large-scale packets originate from the SW Gorlo Strait, travel to the Basin and, in specific cases, are able to reach the western sea shelf. It is suggested that nonlinear IWs evolving into large-scale IWs are generated at the consequent tidal cycles by the interaction of relatively strong barotropic tidal flow with the frontal area located over the bank in the SW Gorlo Strait.

The numerical model used to calculate the propagation of NIW packets generated in the SW Gorlo Strait agrees with the SAR observations and confirms the strong influence of $M_{2}$ tidal cycles. Different IW generation mechanisms can be invoked, but at this stage, in situ information is still lacking. Yet, both SAR observations and model predictions help to recognize that large-scale IW packets emerging from the frontal area in the eastern White Sea can lead to intense large-amplitude NIWs on the western sea shelf. As such, upon reaching the western shelf, nonlinear IWs dissipate to significantly enhance the vertical turbulent exchange. Within such a framework, future investigations using SAR data shall be carried out to help better evaluate the vertical turbulent exchange coefficients, and the effects on the hydrology of the shallow shelf waters.

The results obtained in this study will be effectively used for the planning of future oceanographic experiments to further reveal the generation and propagation properties of IWs in the White Sea, and, primarily, in the southwestern part of the Gorlo Strait - a new hotspot for the generation of the large-scale nonlinear internal waves in the small Arctic Sea.

\section{Acknowledgement}

The support for this study was provided by the Mega-Grant of the Russian Federation Government under Grant №11.G34.31.0078, to support scientific research under the supervision of leading scientist at Russian State Hydrometeorological University, and the French project ANR-09-BLAN-0365-02. IK acknowledge the support from RFBR, research project No. 14-05-31423 mol_a. Envisat ASAR scenes were provided under ESA Cat-1 proposal (C1F-4483).

The authors would like to thank E. Kozlova $\left(\mathrm{IK}^{2} \mathrm{~F}\right)$, E. Zabolotskikh (SOLab), and two anonymous reviewers for their helpful comments and valuable suggestions on improving the quality of the manuscript.

\section{References}

Alpers, W., \& Huang, W. (2011). On the discrimination of radar signatures of atmospheric gravity waves and oceanic internal waves on synthetic aperture radar images of the sea surface. IEEE Transactions on Geoscience and Remote Sensing, 49(3), 1114-1126.

Apel, J. R., \& Gonzalez, F. I. (1983). Nonlinear features of internal waves off Baja California as observed from the SEASAT imaging radar. Journal of Geophysical Research, 88, 4459-4466.

Apel, J. R., Holbrook, J. R., Liu, A. K., \& Tsai, J. J. (1985). The Sulu Sea internal soliton experiment. Journal of Physical Oceanography, 15(12), 1625-1651. doi:10.1175/1520-0485(1985)015 $<1625$ :TSSISE>2.0.CO;2.

Chereskin, T. K. (1983). Generation of internal waves in Massachusetts Bay. Journal of Geophysical Research, 88(C4), 2649-2661. doi:10.1029/JC088iC04p02649.

da Silva, J. C. B., Ermakov, S. A., Robinson, I. S., Jeans, D. R. G., \& Kijashko, S. V. (1998). Role of surface films in ERS SAR signatures of internal waves on the shelf 1. Short-period internal waves. Journal of Geophysical Research, 103 (C4), 8009-8031. doi:10.1029/97JC02725. 
da Silva, J. C. B., New, A. L., \& Azevedo, A. (2007). On the role of SAR for observing "local generation" of internal solitary waves off the Iberian Peninsula. Canadian Journal of Remote Sensing, 33(5), 388-403. doi:10.5589/m07-041.

da Silva, J. C. B., \& Helfrich, K. R. (2008). Synthetic Aperture Radar observations of resonantly generated internal solitary waves at Race Point Channel (Cape Cod). Journal of Geophysical Research, 113(C11016). doi:10.1029/2008JC005004.

da Silva, J. C. B., New, A. L., \& Magalhães, J. M. (2011). On the structure and propagation of internal solitary waves generated at the Mascarene Plateau in the Indian Ocean. Deep-Sea Research Part I, 58, 229-240. doi:10.1016/j.dsr.2010.12.003.

Farmer, D., Li, Q., \& Park, J. (2009). Internal wave observations in the South China Sea: The role of rotation and non-linearity. Atmosphere-Ocean, 47(4), 267-280. doi:10.3137/OC313.2009.

Fu, L. L., \& Holt, B. (1984). Internal waves in the Gulf of California: observations from a spaceborne radar. Journal of Geophysical Research, 89(C2), 2053-2060. doi:10.1029/JC089iC02p02053.

Gerkema, T. (2002). Application of an internal tide generation model to baroclinic spring-neap cycles. Journal of Geophysical Research, 107(C9), 3124. doi:10.1029/2001JC001177.

Glukhovsky, B. H. (1991). Hydrometeorology and hydrochemistry of the Seas of the USSR, Vol. 2: The White Sea, Part 1: Hydrometeorological conditions. Leningrad: Gidrometeoizdat.

Grimshaw, R., Pelinovsky, E., Talipova, T., \& Kurkin, A. (2004). Simulation of the transformation of internal solitary waves on oceanic shelves. Journal of Physical Oceanography, 34, 2774-2791. doi:10.1175/JPO2652.1.

Grimshaw, R., Pelinovsky, E., \& Talipova, T. (2007). Modeling internal solitary waves in the coastal ocean. Surveys in Geophysics, 28, 273-298. doi:10.1007/s10712-007-9020-0.

Grimshaw, R., \& Helfrich, K. (2008). Long-time solutions of the Ostrovsky equation. Studies in Applied Mathematics, 121(1), 71-88. doi:10.1111/j.1467-9590.2008.00412.x.

Grimshaw, R., Helfrich, K. R., \& Johnson, E. R. (2013). Experimental study of the effect of rotation on nonlinear internal waves. Physics of Fluids, 25(5), 056602-056602-24. doi:10.1063/1.4805092.

Groeskamp, S., Nauw, J. J., \& Maas, L. R. M. (2011) Observations of estuarine circulation and solitary internal waves in a highly energetic tidal channel. Ocean Dynamics, 61(11), 1767-1782. doi:10.1007/s10236-011-0455-y.

Helfrich, K. (2007). Decay and return of internal solitary waves with rotation. Physics of Fluids, 19, 026601. doi:10.1063/1.2472509.

Holloway, P. E., Pelinovsky, E., Talipova, T., \& Barnes, B. (1997). A nonlinear model of internal tide transformation on the Australian North West Shelf. Journal of Physical Oceanography, 27, 871-896. doi:10.1175/1520-0485(1997)027<0871:ANMOIT>2.0.CO;2.

Jackson, C. R. (2004). An atlas of internal solitary-like waves and their properties. (2nd ed.). Global Ocean Associates, Alexandria, VA.

Jackson, C. R., da Silva, J. C. B., \& Jeans, G. (2012). The generation of nonlinear internal waves. Oceanography, 25(2), 108-123. doi:10.5670/oceanog.2012.46.

Jakobsson, M., Mayer, L. A., Coakley, B., Dowdeswell, J. A., Forbes, S., Fridman, B., Hodnesdal, H., Noormets, R., Pedersen, R., Rebesco, M., Schenke, H. -W., Zarayskaya, Y., Accettella, D., Armstrong, A., Anderson, R. M., Bienhoff, P., Camerlenghi, A., Church, I., Edwards, M., Gardner, J. V., Hall, J. K., Hell, B., Hestvik, O. B., Kristoffersen, Y., Marcussen, C., Mohammad, R., Mosher, D., Nghiem, S. V., Pedrosa, M. T., Travaglini, P. G., \& Weatherall, P. (2012). The International Bathymetric Chart of the Arctic Ocean (IBCAO) Version 3.0. Geophysical Research Letters, 39, L12609. doi:10.1029/2012GL052219.

Johannessen, J. A., Kudryavtsev, V., Akimov, D., Eldevik, T., Winther, N., \& Chapron, B. (2005). On radar imaging of current features: 2. Mesoscale eddy and current front detection. Journal of Geophysical Research, 110, C07017. doi:10.1029/2004JC002802.

Kagan, B. A., \& Timofeev, A. A. (2005). Dynamics and energetics of surface and internal semidiurnal tides in the White Sea. Izvestiya, Atmospheric and Oceanic Physics, 41(4), 498 - 512.

Klemas, V. (2012). Remote sensing of ocean internal waves: An overview. Journal of Coastal Research, 28(3), 540-546. doi:10.2112/JCOASTRES-D-11-00156.1.

Kozlov, I. E., Kudryavtsev, V. N., Johannessen, J. A., Chapron, B., Dailidienè, I., \& Myasoedov, A. G. (2012). ASAR imaging for coastal upwelling in the Baltic Sea. Advances in Space Research, 50(8), 1125-1137. doi:10.1016/j.asr.2011.08.017.

Kudryavtsev, V., Akimov, D., Johannessen, J., \& Chapron, B. (2005). On radar imaging of current features: 1. Model and comparison with observations. Journal of Geophysical Research, 110, C07016. doi:10.1029/2004JC002505. 
Kurapov, A. L., Allen, J. S., \& Egbert, G. D. (2010). Combined effects of wind-driven upwelling and internal tide on the continental shelf. Journal of Physical Oceanography, 40, 737-756. doi:10.1175/2009JPO4183.1.

Liu, A. K., Chang, Y. S., Hsu, M. -K., \& Liang, N. K. (1998). Evolution of nonlinear internal waves in the East and South China Seas. Journal of Geophysical Research, 103(C4), 7995-8008. doi:10.1029/97JC01918.

Maxworthy, T. (1979). A note on the internal solitary waves produced by tidal flow over a threedimensional ridge. Journal of Geophysical Research, 84(C1), 338-346. doi:10.1029/JC084iC01p00338.

Morozov, E. G., \& Paka, V. T. (2010). Internal waves in a high-latitude region. Oceanology, 50(5), 668-674, doi:10.1134/S0001437010050048.

Moum, J. N., Farmer, D. M., Smyth, W. D., Armi, L., \& Vagle, S. (2003). Structure and generation of turbulence at interfaces strained by internal solitary waves propagating shoreward over the continental shelf. Journal of Physical Oceanography, 33, 2093-2112. doi:10.1175/15200485(2003)033<2093:SAGOTA>2.0.CO;2.

Nash, J. D., \& Moum, J. (2005). River plumes as a source of large-amplitude internal waves in the coastal ocean. Nature, 437, 400-403. doi:10.1038/nature03936.

Osborne, A. R., \& Burch, T. L. (1980). Internal solitons in the Andaman Sea. Science, 208, 451-460.

Ostrovsky, L. A. (1978). Nonlinear internal waves in a rotating ocean. Oceanology, 18(2), 119-125.

Pantiulin, A. N. (2012). Structure and dynamics of the White Sea. In A. P. Lisitzyn (Ed.), System of the White Sea, Vol. II, Water basin interacting with atmosphere, cryosphere, river runoff and biosphere (pp. 309-378). Nauchny Mir, Moscow.

Semenov, C. V., \& Luneva, M. V. (1999). Combined effect of tide, stratification, and vertical turbulent mixing on the formation of hydrophysical fields in the White Sea. Izvestiya, Atmospheric and Oceanic Physics, 35(5), 660-678.

Serebryany, A., Paka, V., \& Korzh, A. (2009). Internal hydraulic jumps in the White Sea. Geophysical Research Abstracts, 11, EGU2009-11651.

Shapiro, G. I., Latché, L., \& Pantiulin, A. N. (2003). Mixing processes in the Gorlo Strait of the White Sea. Oceanology, 43(1), 26-31.

Simpson, J. H., \& Hunter, J. R. (1974). Fronts in the Irish Sea. Nature, 250, 404-406.

Small, J., Sawyer, N. C., \& Scott, J. C. (1999). The evolution of an internal bore at the Malin shelf break. Annales Geophysicae, 17, 547-565. doi:10.1007/s00585-999-0547-x.

Small, J. (2001). A nonlinear model of the shoaling and refraction of interfacial solitary waves in the ocean. Part I: Development of the model and investigations of the shoaling effect. Journal of Physical Oceanography, 31, 3163-3183. doi:10.1175/1520-0485(2001)031<3163:ANMOTS>2.0.CO;2.

Vlasenko, V., Stashchuk, N., Hutter, K., \& Sabinin, K. (2003). Nonlinear internal waves forced by tides near the critical latitude. Deep Sea Research Part I, 50 (2), 317-338. doi:10.1016/S09670637(03)00018-9.

Zhao, Z., Klemas, V., Zheng, Q., \& Yan, X. -H. (2003). Satellite observation of internal solitary waves converting polarity. Geophysical Research Letters, 30(19). doi:10.1029/2003GL018286.

Zheng, Q., Klemas, V., Yan, X. -H., \& Pan, J. (2001). Nonlinear evolution of ocean internal solitons propagating along an inhomogeneous thermocline. Journal of Geophysical Research, 106(C7), 1408314094. doi:10.1029/2000JC000386.

Zimin, A. V. (2012). Internal waves on the White Sea shelf according to observations. Oceanology, 52(1), 11-20. doi:10.1134/S0001437011060245.

Zimin, A. V. (2013). Short-period variability of hydrophysical fields and internal wave characteristics during the semidiurnal tidal cycle on the White Sea shelf. Oceanology, 53(3), 259-268. doi:10.1134/S0001437013020173. 


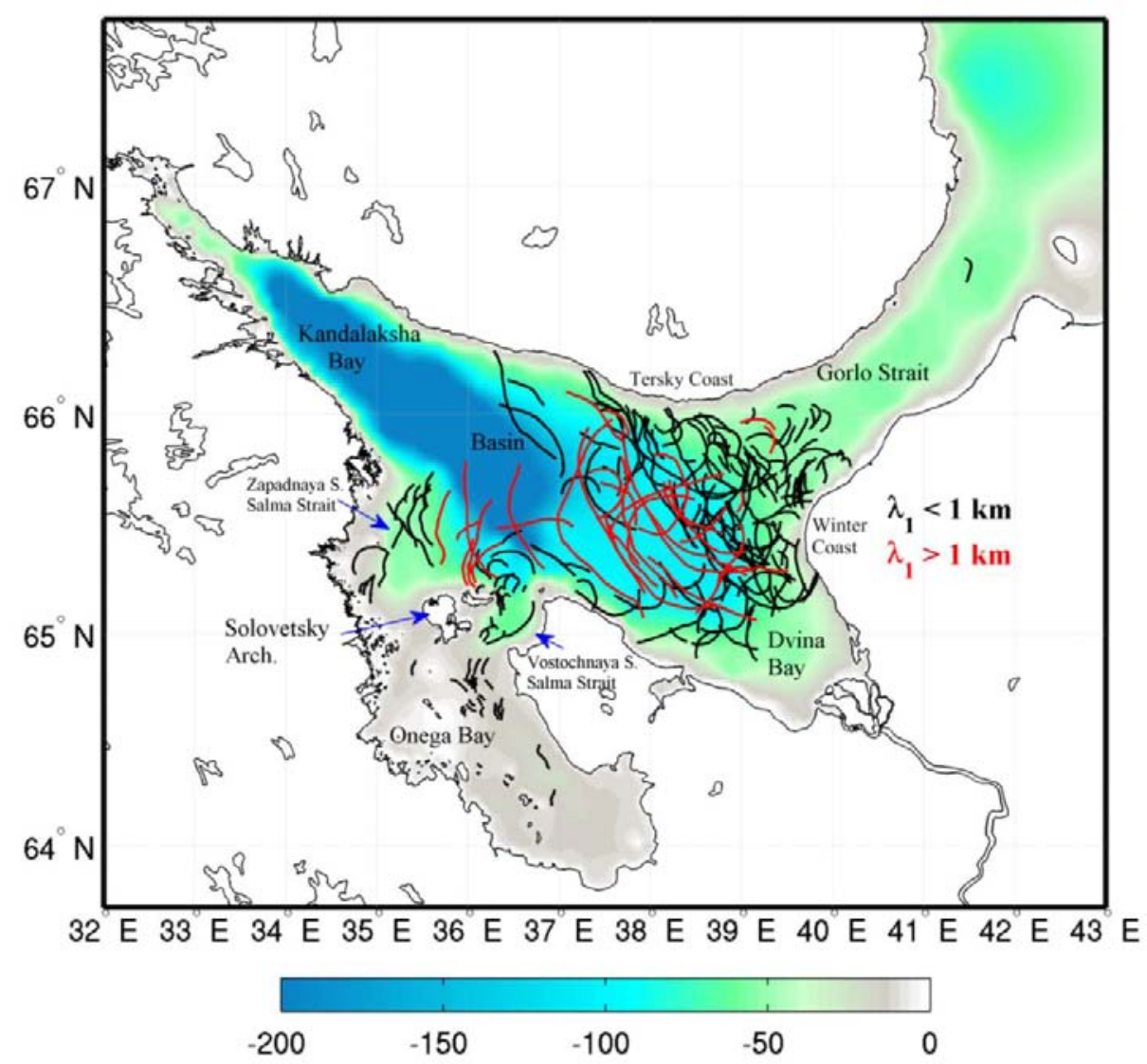

Figure 1. Distribution map of internal wave locations in the White Sea detected in the Envisat ASAR images in summer period 2007-2011. The leading waves with wavelengths up to $1 \mathrm{~km}$ (larger than $1 \mathrm{~km}$ ) are shown in black (red). Bathymetry map is obtained from IBCAO Grid Version 3.0 (Jakobsson et al., 2012). 


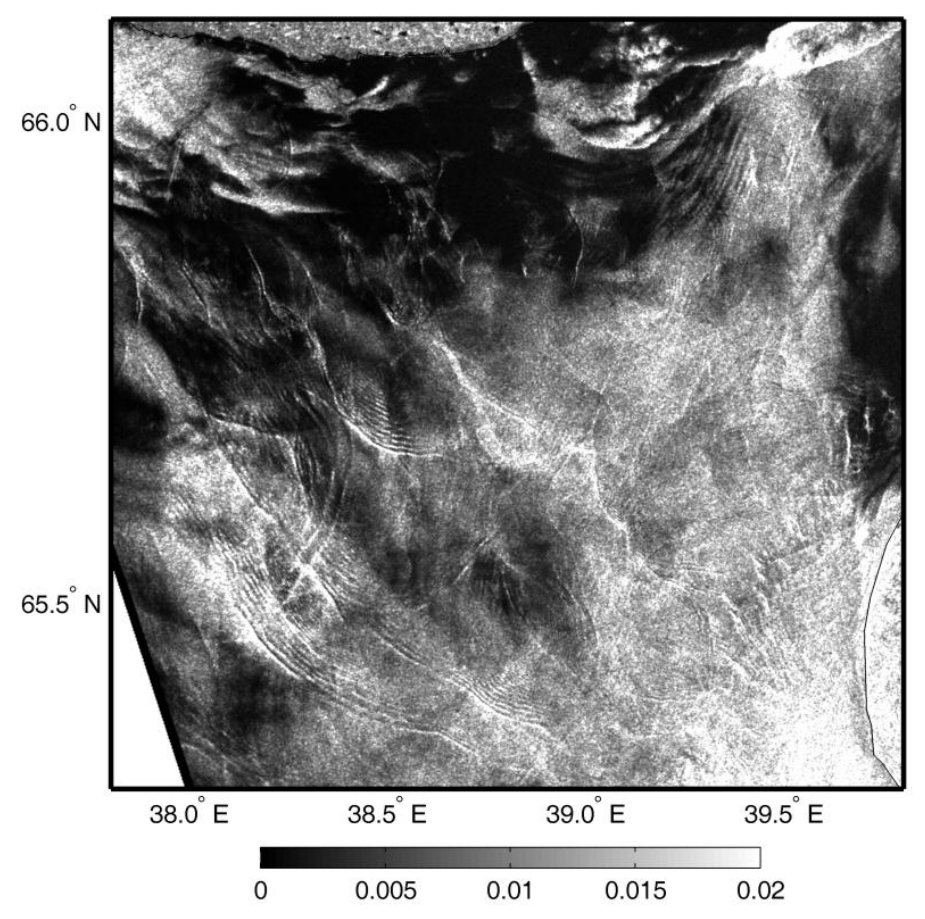

Figure 2. Envisat ASAR image of a region southwest of the Gorlo Strait taken on August 13, 2010 (18:30 UTC) showing distinct sea surface patterns of long-crested internal wave packets propagating southwest. (C) ESA

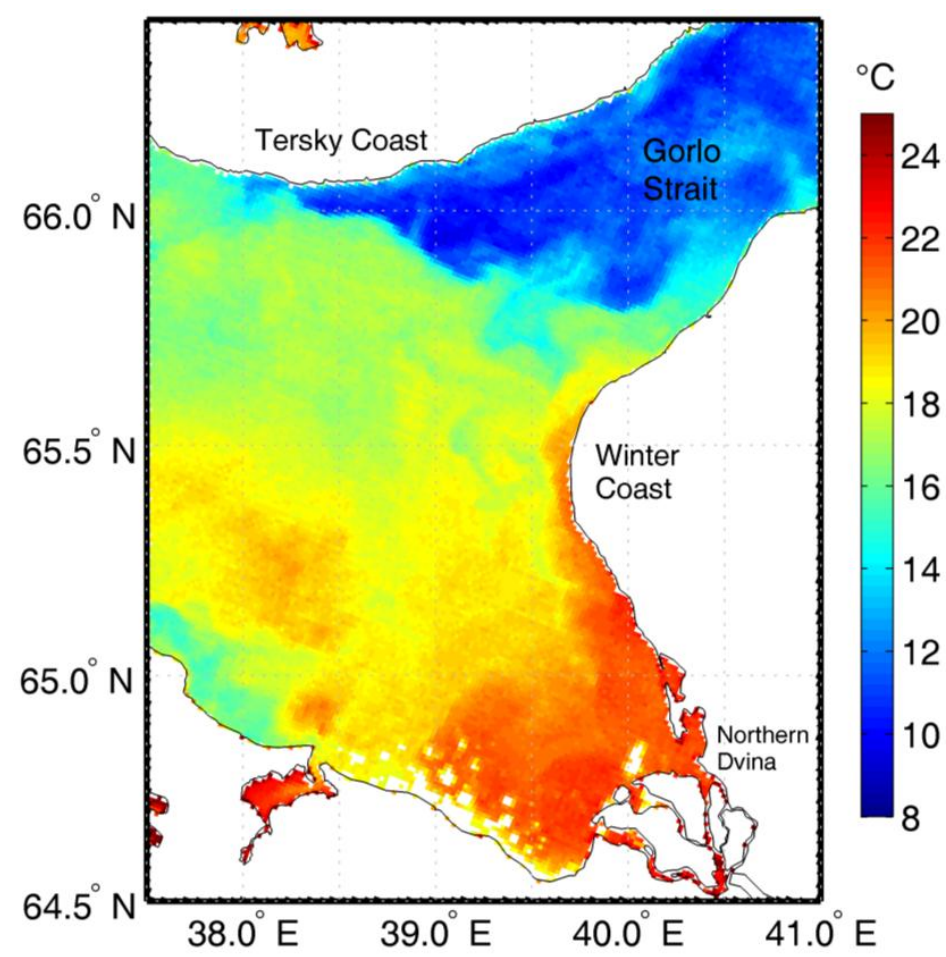

Figure 3. Terra MODIS SST map of the eastern White Sea acquired on August 4, 2010 (18:05 UTC) depicting the complex frontal zone in the SW Gorlo Strait. ( NASA 

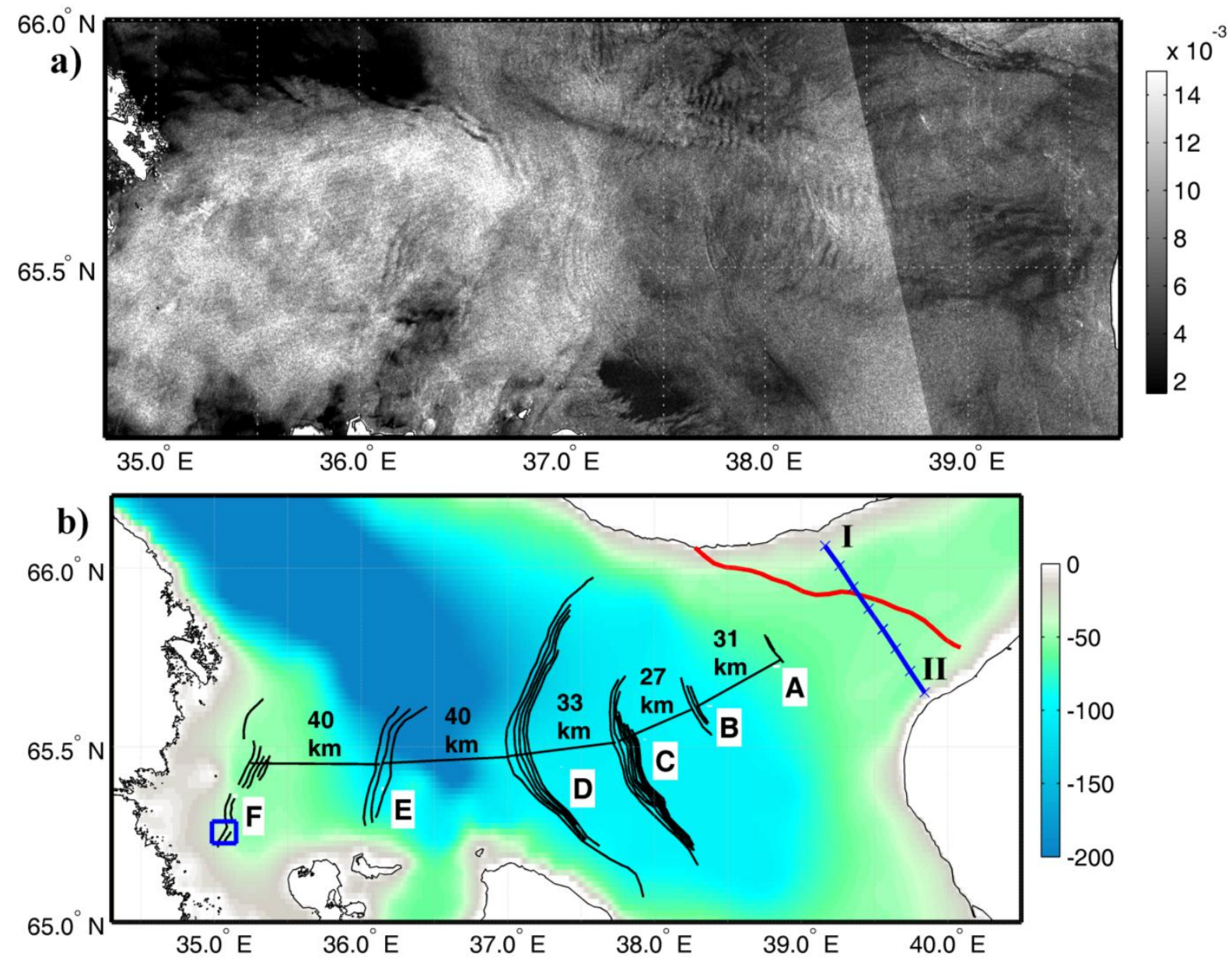

Figure 4. a) Envisat ASAR image acquired over the White Sea on July 21, 2010 (18:52 UTC) depicting large-scale internal wave packets emerging from the frontal area in the southwestern Gorlo Strait. b) Bathymetry map of the central White Sea showing the locations of large-scale IW packets $\boldsymbol{A}-\boldsymbol{F}$ (black lines) observed in the ASAR image (a) with the marked positions of the density front in the SW GS (red line), oceanographic section across the SW GS (blue line with crosses), and mooring site in the Zapadnaya Solovetskaya Salma Strait (blue box). @ ESA 


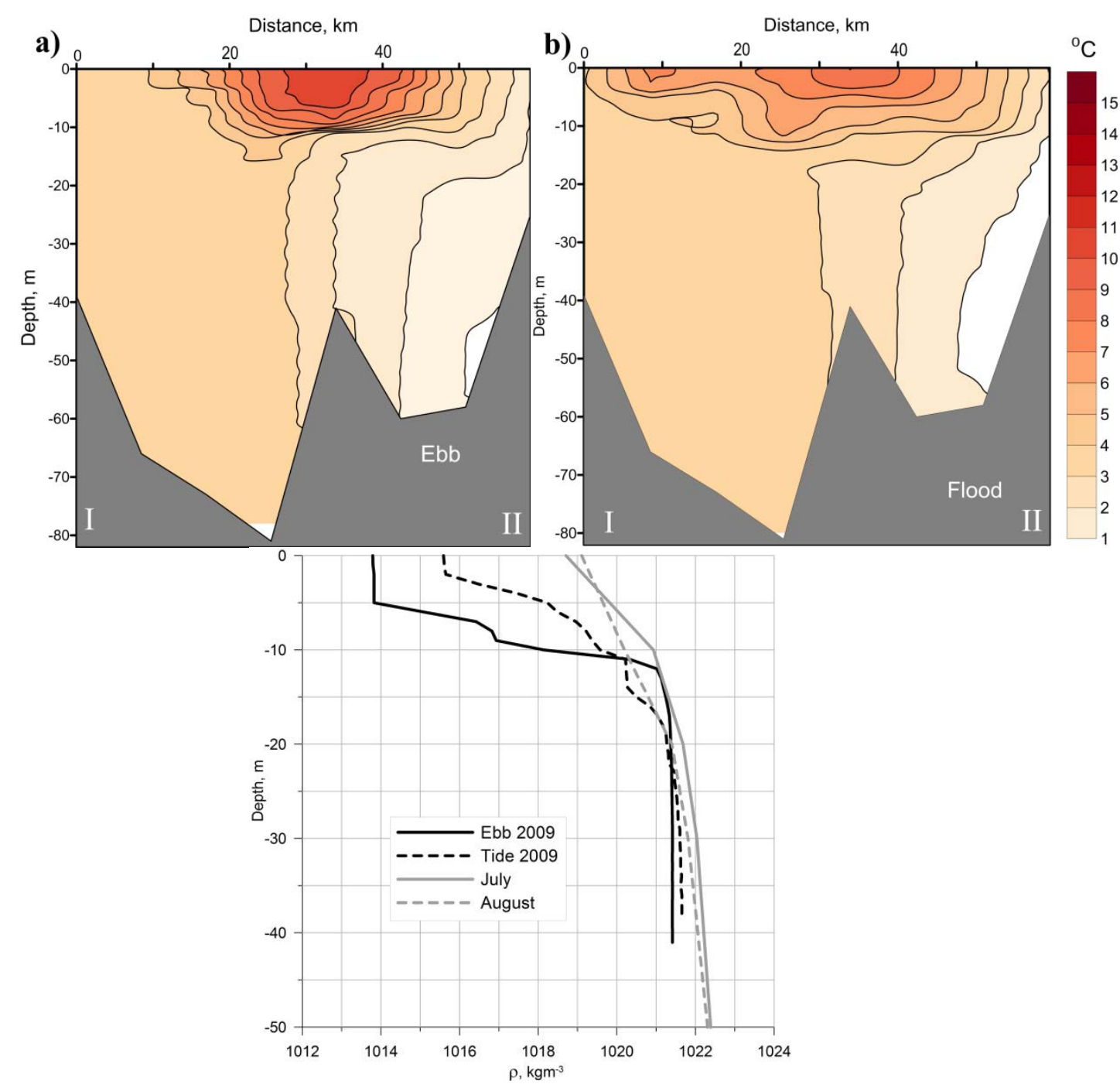

Figure 5. Vertical plots of temperature during the ebb (a) and flood (b) tide obtained from ship-borne CTD measurements on June 29, 2009 along the section crossing the SW GS (shown on Fig. 4 as blue line with crosses), (c) vertical density profiles over the underwater bank from the same ship-borne data in the ebb (black solid line) and flood (black dashed line) tide, and from climatology data for July (grey solid line) and August (grey dashed line). 


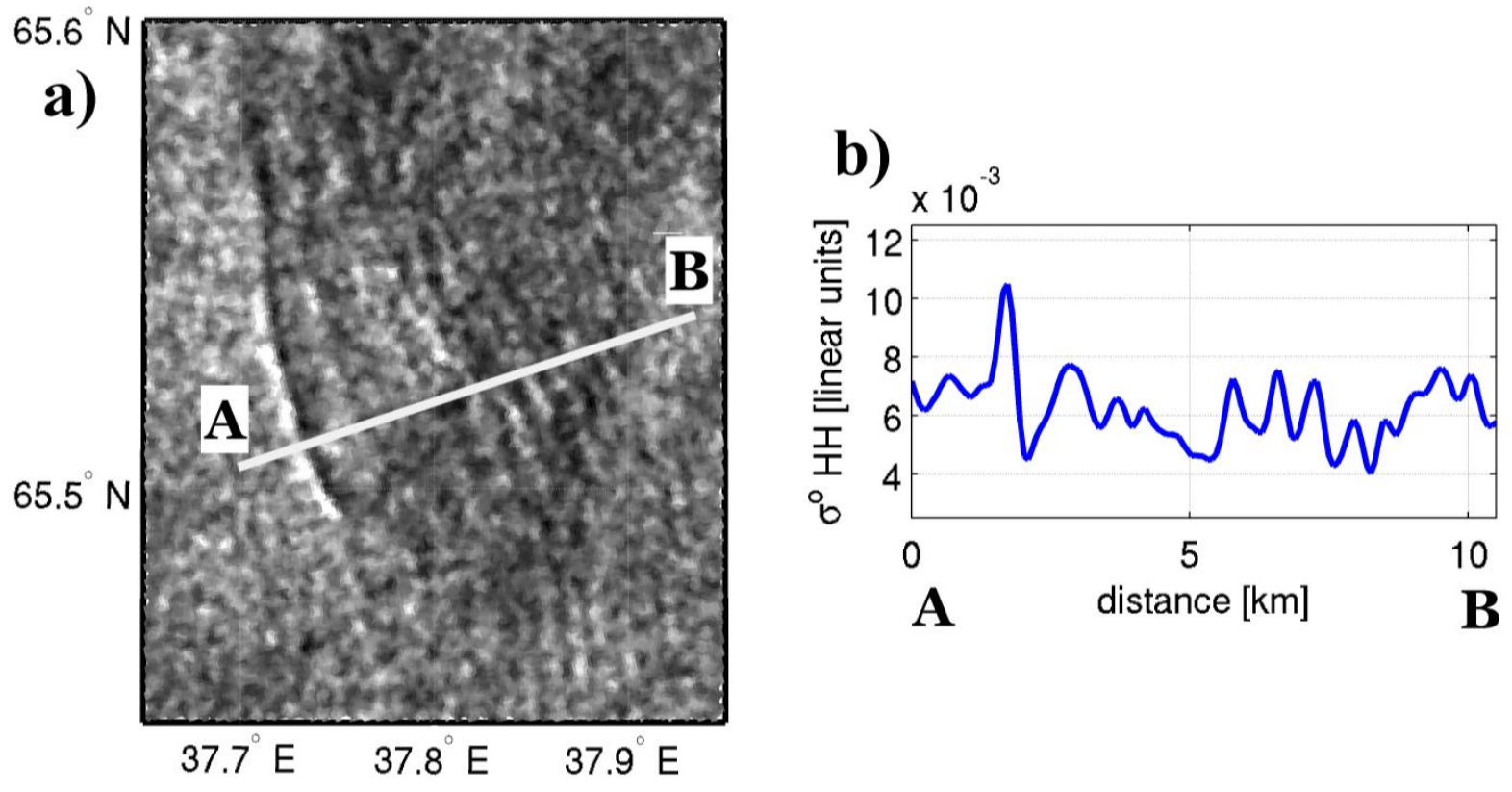

Figure 6. a) The fraction of the Envisat ASAR image presented on Fig. 4 (a) showing a zoom of the packet C. b) SAR image backscatter profile along the section A-B crossing the IW packet $C$, illustrating the evolution of the initial solitons (two leftmost oscillations on the profile) accompanied with a tail of short-scale oscillations at some distance.

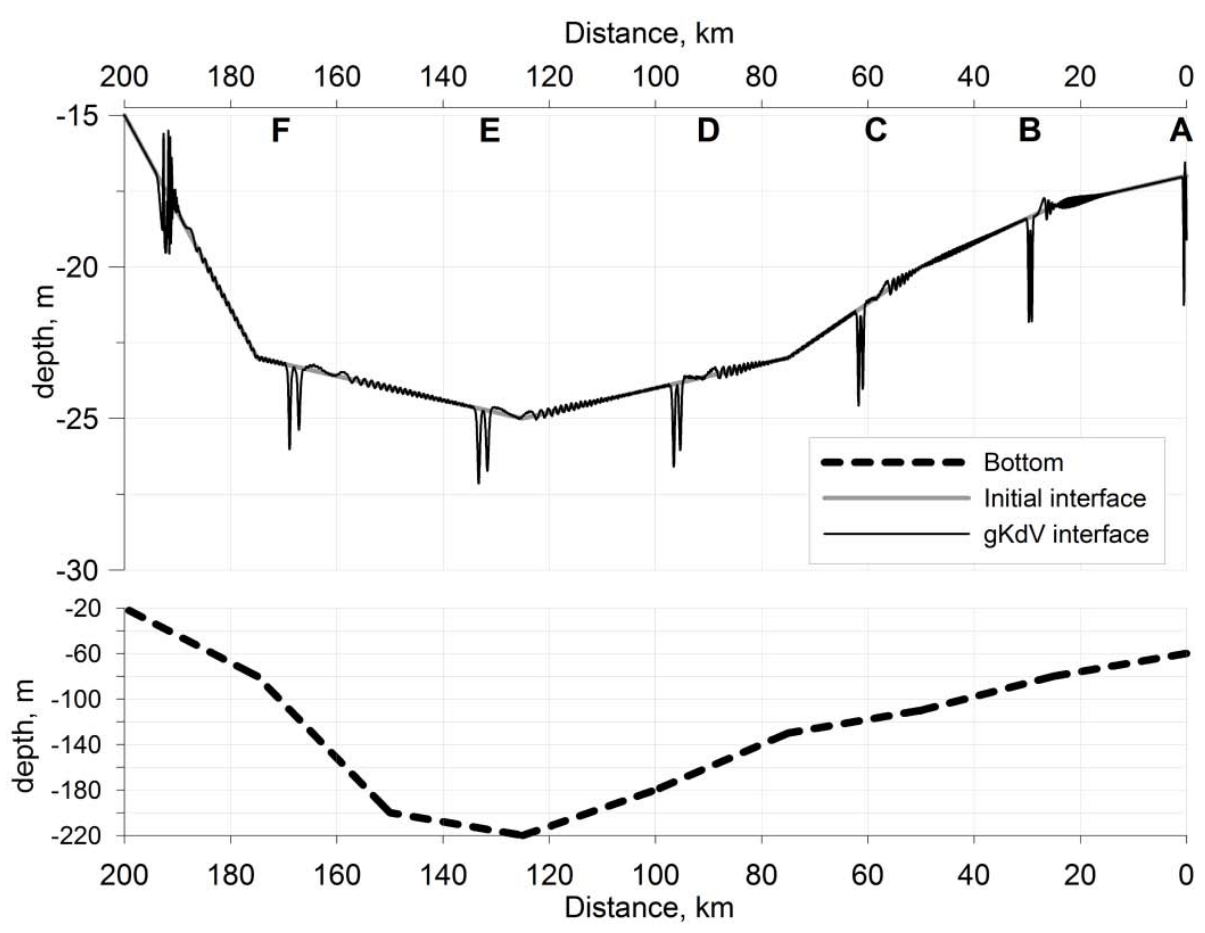

Figure 7. Results of numerical calculation of two-wave packet propagation along the interface between upper and lower layers according to the gKdV model. Symbols $\boldsymbol{A}-\boldsymbol{F}$ are locations of IW packets observed in the ASAR image on Fig. 4. 


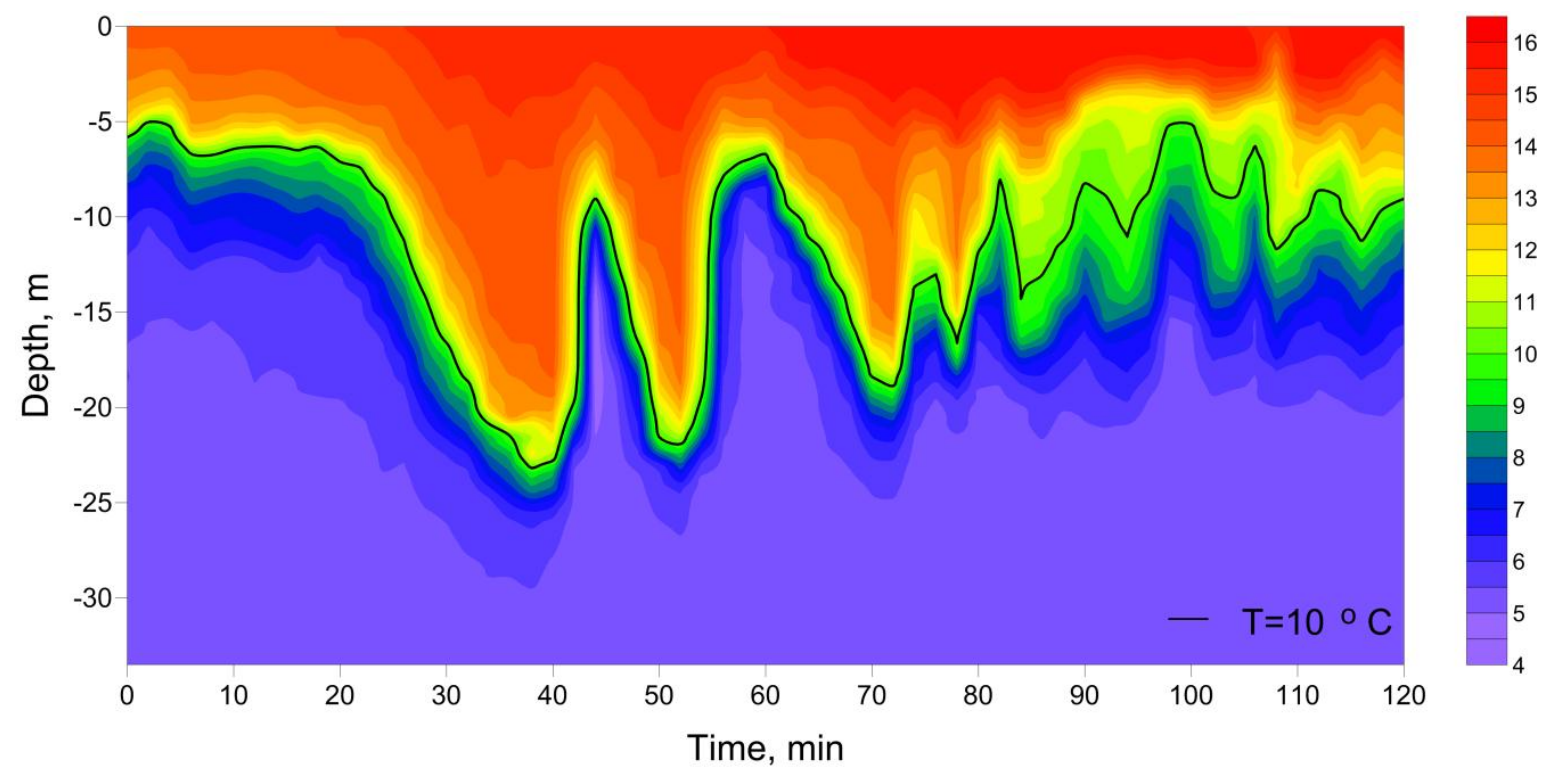

Figure 8. A train of intensive nonlinear IWs registered during the field experiment in the Zapadnaya Solovetskaya Salma Strait (blue box on Fig. 4) on August 8, 2010. 